DOI https://doi.org/10.36059/978-966-397-107-0/153-176

\title{
MATRIX GAMES AND STATISTIC CRITERIA
}

\section{Muliava O. M.}

\section{INTRODUCTION}

Let us consider game situations in modeling of various aspects of work of a really existing enterprise. This is a very difficult situation, as not only the rules and customs that govern the contracting process, but also some situations that give the individual or company the opportunity to enter into an agreement on particularly favorable terms, play a role.

A common feature of different situations is that when making his/her own decision, each participant must have an idea of the decisions made by the other participant.

However, unfortunately, game theory has proven to be inadequate to address all of the problems posed by the need for organizations with many participants. However, its application has made it much easier to investigate some simple cases.

\section{Problem statement}

Consider the problem of supply of raw materials.

Suppose that a firm $A$ entered into an agreement with another company $B$ for the supply of perishable raw materials, valued at $\$ 100$ a day.

If raw materials are not available during the day, the firm $A$ incurs losses of $\$ 400$. from the downtime of the workers.

It can use her own transportation (an additional cost of \$50), but experience shows that in half of the cases, the transport returns empty.

It is possible to increase the likelihood of receiving raw materials up to $80 \%$ if you first send your representative to the company $B$, but this requires an additional cost of $\$ 40$.

It is possible to order a daily rate of raw material from another company at a price up to $50 \%$ higher, but in addition to transportation costs $(\$ 50)$, there may be additional costs of $\$ 30$ associated with the overtime of the teams that sell unnecessary raw materials if a centralized supply arrives on the same day. 
What strategy should firm $A$ follow if it is not known in advance whether a centralized supply of raw materials will occur or not?

To solve this problem, first of all, we will list the possible strategies of the supplier (firm $B$ ):

$B_{1}$ - delivery on time;

$B_{2}-$ no delivery.

The company $A$, according to the condition of the problem, has four strategies:

$A_{l}$ - Take no further action;

$A_{g}-$ send to company $B$ own transport;

$A_{3}$ - send to company $B$ own representative and transport;

$A_{4}$ - order additional raw materials from another company.

In the general case, if the first player (firm $A$ ) $m$ has possible strategies, and the second one $-n$, then always $m, n$ possible situations are created, each of which corresponds to a certain payment of one player to the other.

There are a total of 8 situations that describe all combinations of four firm strategies $A$ and two company $B$ strategies

These situations and their associated losses and costs are presented in Table. 1.

Table 1

\begin{tabular}{|c|c|c|c|c|c|c|}
\hline \multirow[b]{2}{*}{ Cuтуциia } & \multicolumn{6}{|c|}{ Дениі витроти фарми $A$} \\
\hline & $\begin{array}{l}\text { Baptictb } \\
\text { спровния }\end{array}$ & $\begin{array}{l}\text { Зиттин } \\
\text { ей } \\
\text { простон }\end{array}$ & $\begin{array}{c}\text { Транепортиі } \\
\text { внтритн }\end{array}$ & $\begin{array}{l}\text { Витрато на } \\
\text { вірияхения }\end{array}$ & $\begin{array}{c}\text { Витрзтя } \\
\text { нам понан - } \\
\text { нормовану } \\
\text { роботу }\end{array}$ & $\begin{array}{l}\text { Beboro } \\
\text { nens }\end{array}$ \\
\hline$A_{1}-B_{1}$ & 100 & 0 & 0 & 0 & 0 & 100 \\
\hline$A_{1}=B_{2}$ & 0 & 400 & 0 & 0 & 0 & 400 \\
\hline$A_{2}=B_{1}$ & 100 & 0 & 50 & 0 & 0 & 150 \\
\hline$A_{i}-B_{1}$ & 50 & 200 & 50 & 0 & 0 & 300 \\
\hline$A_{1}-B_{1}$ & 100 & 0 & 50 & 40 & 0 & 190 \\
\hline$A_{3}-B_{1}$ & 80 & 80 & 50 & 40 & 0 & 250 \\
\hline$A_{4}=B_{1}$ & 250 & 0 & 50 & 0 & 30 & 330 \\
\hline$A_{4}-B_{7}$ & 150 & 0 & 50 & 0 & 0 & 200 \\
\hline
\end{tabular}


In many situations, table. 1 becomes cumbersome and incomprehensible, it is more convenient to move from it to an additional payment matrix A. It is a rectangular matrix and has $t$ rows (by the number of first player strategies) and n columns (by the number of second player strategies).At the intersection of the irows and the jcolumns, the second player's payment is placed first in the situation where the $i$ strategy is applied by the first player and $j$ strategy by the second. If the second player wins, the payment will have minus.

The payment matrix in the problem (game) under consideration has a dimension of $4 \times 2$ and is shown in Table. 2. All payments have a negative sign because in this task they determine the costs of the firm $A$.

Table 2

\begin{tabular}{|c|c|c|}
\hline \multirow{2}{*}{$\begin{array}{c}\text { Crparerï̈ } \\
\text { фірми } A\end{array}$} & \multicolumn{2}{|c|}{ Cтратегї фірми $\boldsymbol{B}$} \\
\hline & $\boldsymbol{B}_{1}$ & $\boldsymbol{B}_{\mathbf{2}}$ \\
\hline $\boldsymbol{A}_{1}$ & -100 & -400 \\
\hline$A_{2}$ & -150 & -300 \\
\hline$A_{3}$ & -190 & -250 \\
\hline$A_{4}$ & -330 & -200 \\
\hline
\end{tabular}

Payment Matrix A looks like

$$
A=\left(\begin{array}{rr}
-100 & -400 \\
-150 & -300 \\
-190 & -250 \\
-330 & -200
\end{array}\right)
$$

The task of firm $A$ is to find the optimal strategy that ensures the minimum of expected losses in the conditions of uncertainty of the supplier's behavior (firm $B$ ). Choosing a company behavior strategy $A$ under the conditions described in table.2, depends on the reliability of the supplier, which is quantified in terms of probability. For example, let it be $40 \%$ (meaning that delivery is timely with a probability of 0.4 ). Then the expected losses (negative gain) of the company $A$ when applying the first pure strategy $A$, are

$$
S_{1}(0,4)=-100 \cdot 0,4-400 \cdot 0,6=-280 \text { y.o., }
$$

and when applying the fourth one,

$$
S_{4}(0,4)=-330 \cdot 0,4-200 \cdot 0,6=-252 \text { y.o., }
$$


We see that costs have decreased. If you calculate losses when applying other strategies, then the best strategy will be $A_{3}$. In fact, using the second strategy, the firm And will bear the losses,

$$
S_{2}(0,4)=-150 \cdot 0,4-300 \cdot 0,6=-240 \text { y.o., }
$$

and when using the third strategy, only

$$
S_{3}(0,4)=-190 \cdot 0,4-250 \cdot 0,6=-226 \text { y.o. }
$$

\section{Geometric and economic interpretations of game theory problem solving}

Let us give a geometric interpretation of the game (problem) under consideration ${ }^{1}$.

To do this, we draw the horizontal axis of the reliability of the supplier (firm $V$ ), which is measured by probabilities in the range $0-1$ and denote it $\boldsymbol{x}_{1}$. The value of $\boldsymbol{x}_{\mathbf{2}}=\mathbf{1}-\boldsymbol{x}_{\mathbf{1}}$ is thus the magnitude of unreliability of the supplier.

The numbers $\boldsymbol{x}_{\mathbf{1}}$ and $\boldsymbol{x}_{\mathbf{2}}$, which are equal to one, indicate the probability that the supplier of pure strategies $\boldsymbol{B}_{\mathbf{1}}$ and $\boldsymbol{B}_{\mathbf{2}}$ are used in each party. The set of strategies $\boldsymbol{B}_{1}$ and $\boldsymbol{B}_{2}$, which have a probability estimate of $\boldsymbol{x}_{\mathbf{1}}$ and $\boldsymbol{x}_{\mathbf{2}}$ their implementation is called mixed strategy.

The points $x_{1}=0$ and $x_{1}=1$ in Fig. 1 correspond to the second and first pure strategies of the firm $B$, and all points $0<x_{1}<1$ on the segment - to the mixed strategies. It is clear that there is an infinite number of mixed strategies for each player.

Let us plot the graphics of the firm's $A$ costs when applying its pure strategies against the company's mixed strategy $B$. Let's start with the first strategy. If the supplier is absolutely reliable (that is, always applies the strategy $B_{1}$ and means $x_{1}=1, x_{2}=0$ ), the costs of the firm $A$ are equal in accordance with the payment matrix -100 USD.

Let us set a point with coordinates $(1 ;-100)$.

If the supplier is completely unreliable (that is, always applies the strategy $B_{2} ; x_{1}=0, x_{2}=1$ ), then the cost of the company $A$ equals $400 \$$. and it is necessary to set the point with coordinates $(0 ;-400)$.

\footnotetext{
${ }^{1}$ Kofman A. Methods and models of operations research. Moscow: World, 1977, 432p.
} 


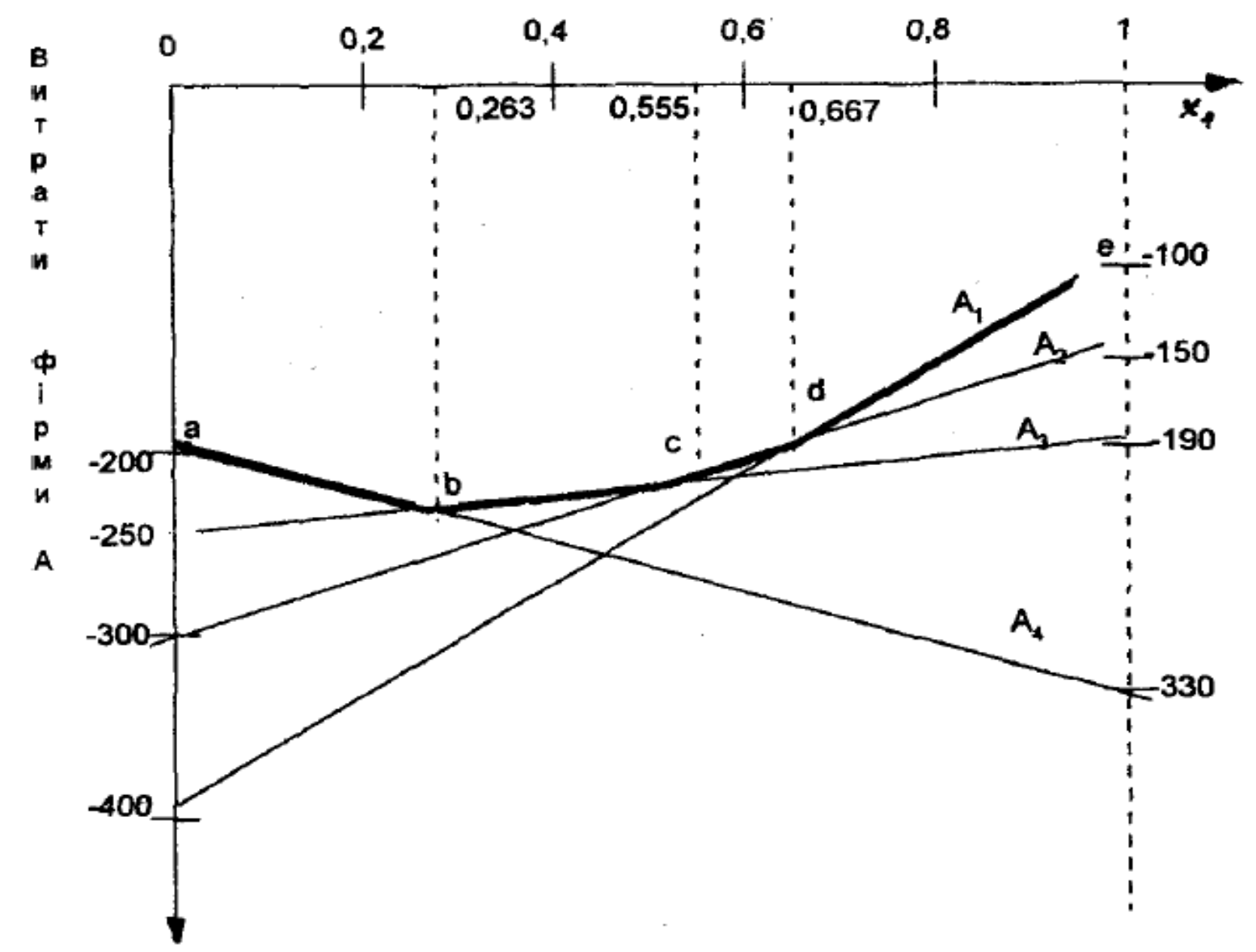

Fig. 1

If the reliability of the firm $B 0<\mathrm{x}_{1}<1$, then the daily expenses of the firm $A$, which applies the first strategy against the mixed strategy of the supplier, depend on the probability $x_{1}$, and equal

$S_{1}\left(x_{1}\right)=-100 x_{1}-400 x_{2}=-100 x_{1}-400\left(1-x_{1}\right)=300 x_{1}-400$.

The graph of this function is a straight line, which is shown in Fig. $1 \mathbf{A}_{\mathbf{1}}$.

Similarly, the graphs of the functions of the expected costs of the firm $A$ when applying each pure strategy against the mixed strategies of the supplier company $B$ :

$$
\begin{aligned}
& S_{2}\left(x_{1}\right)=-150 x_{1}-300 x_{2}=-150 x_{1}-300\left(1-x_{1}\right)=150 x_{1}-300 ;(2) \\
& S_{3}\left(x_{1}\right)=-190 x_{1}-250 x_{2}=-190 x_{1}-250\left(1-x_{1}\right)=60 x_{1}-250 ; \quad(3) \\
& S_{4}\left(x_{1}\right)=-330 x_{1}-220 x_{2}=-330 x_{1}-200\left(1-x_{1}\right)=130 x_{1}-200,(4) \\
& \text { which are respectively indicated in pic. } 1 \text { as } A_{2}, A_{3}, A_{4} .
\end{aligned}
$$


With the reliability of the supplier $\boldsymbol{x}_{\mathbf{1}}=\mathbf{0 , 4}$ to the intersection with the lines of functions of the expected costs of the company $A$ we find out that the strategy $A_{3}$, that will provide the minimum cost -226 USD will be optimal.

If the reliability of the provider is $\boldsymbol{x}_{\mathbf{1}} \leq \mathbf{0 , 2 6 3}$, it is better to use the fourth strategy; with the reliability of the supplier $0,263 \leq x_{1} \leq \mathbf{0 , 5 5 5}$ the optimal strategy will be $A_{3}$, at $\mathbf{0 , 5 5 5} \leq \boldsymbol{x}_{\mathbf{1}} \leq \mathbf{0 , 6 7 7}-\boldsymbol{A}_{\mathbf{2}}$, at $0,667 \leq x_{1} \leq 1-A_{1}$, (see Fig. 1).

These critical reliability values are derived from the overall solution of equations (1) - (4), which are in pairs: (3) and (4) - Point $b$, (2) and (3) $-\operatorname{dot} c$, (1) and (2) $-\operatorname{dot} d$.

The following is a broken line abccde shows how the expenses of the firm $A$ when the supplier's reliability changes to 0 to 1 are changed.

As you can see from the graph, the increase of the supplier's reliability does not automatically reduce the cost of the firm $A$. In fact, when the provider's reliability grows from 0 to 0.263 , the company costs $A$ increase from -200 to

$$
S_{4}(0,263)=-200-130 \cdot 0,263=-243,2 y . o .
$$

The increase in costs is due to the fact that the raw material is purchased from the second supplier, and the irregular deliveries of the main supplier (with a probability of 0.263 ) lead to additional costs.

With the reliability of the supplier $\boldsymbol{x}_{\mathbf{1}}=\mathbf{0 , 2 6 3}$ cost of the firm $A$ maximum of all possible at a reasonable choice of the firm $A$ Their strategies (this maximum depends on the values of the conditionally selected costs (see table1)).

If the game was antagonistic, that is, the supplier wanted to inflict maximum damage to the company $A$, its optimal reliability would have to be equal to $\boldsymbol{x}_{\mathbf{1}}=\mathbf{0 , 2 6 3}$. At the same time, the company's $A$ costs would have been 234.2 and the optimal one would be the strategy $A_{3}$ and $\boldsymbol{A}_{\mathbf{4}}$, (point $b$ is at the intersection of $\operatorname{lines} A_{3}$ and $\boldsymbol{A}_{\mathbf{4}}$ ). In fact, substituting $\boldsymbol{x}_{\mathbf{1}}=\mathbf{0 , 2 6 3}$ into the equation (3), (4), we get

$$
S_{3}(0,236)=S_{4}(0,236)=-234,2 \text { y. o. }
$$

Due to the fact that the company-supplier seeks to inflict firm $A$ maximum damage, the latter can not choose any one of the net strategies $A_{3}$ or $A_{4}$, for in this case, if the firm $B$ will change the reliability of deliveries in the lesser side of $\boldsymbol{x}_{\mathbf{1}}=\mathbf{0 , 2 6 3}$ (in the case of the Strategy $\boldsymbol{A}_{\mathbf{3}}$ ) 
or in a bigger side (in the case of a strategy $A_{4}$ ), losses will increase and be greater than $-234,2 \$$.

As in the antagonistic game the first and second strategies of the firm $A$ are ineffective, consider the possibility of finding a mixed strategy $A_{3} \mathrm{i}$ $\boldsymbol{A}_{\mathbf{4}}$, with such probabilities of application, in which the losses of firm $A$ would not be greater than $\$ 234.2$ under any strategies of firm $B$. We will construct the chart of expenses of the firm $A$, which applies its mixed strategy, consisting of pure strategies $A_{3}$ i $\boldsymbol{A}_{\mathbf{4}}$ against each clear strategy $\boldsymbol{B}_{\mathbf{1}}$ i $B_{2}$ of firm $B$ (fig. 2).

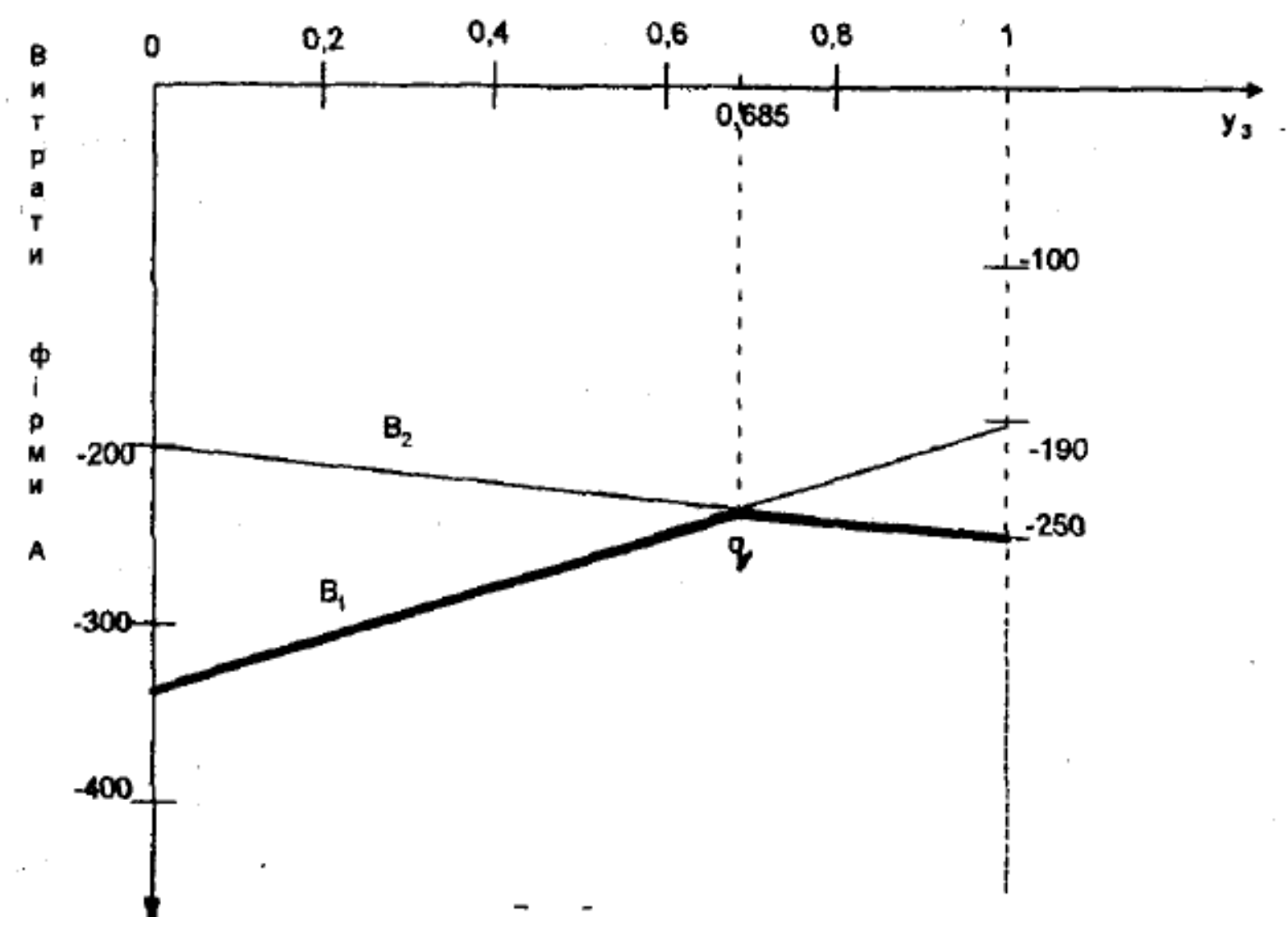

Fig. 2

Using $y_{3}$ let's denote the probability of application of strategy $A_{3}$, and using $y_{4}-$ strategy $\boldsymbol{A}_{\mathbf{4}}\left(\boldsymbol{y}_{3}+\boldsymbol{y}_{\mathbf{4}}=\mathbf{1}\right)$. From a graph constructed similarly to the graph in Fig.1, it is seen that the optimal mixed strategy of the firm $A$ includes the strategies $A_{3}$ and $A_{4}$, which are applied with probabilitie $\mathrm{s}_{3}=0,685$ and $y_{4}=0,315$. 
The optimal costs of firm $A$ (called in the case of an antagonistic game the price of the game) equal to the ordinates of the intersection point $\mathrm{q}$. Substituting $y_{3}=0,685$ into any of the equations of the straight $S_{1}\left(y_{3}\right)=140 y_{3}-330 ; S_{2}\left(y_{3}\right)=-50 y_{3}-200$, we get the same cost value - \$234.2, which was previously calculated. Figure 2 shows that in an antagonistic game firm D should not deviate from its optimal mixed strategy $y_{1}=y_{2}=0 ; y_{3}=0.685 ; \mathrm{y}_{4}=0.315$ as costs increase (in the direction of the lines shown). When $y_{3}<0,685$ firm $B$ will start to apply a pure strategy $\mathrm{B}_{1}$,when $y_{3}>0,685$ - a pure stategy $B_{2}$ and will cause losses to firm $A$ greater than $-234,2 \$$.

Thus, if the game was antagonistic (i.e each player inflicts maximum damage to the opponent), players should be recommend the following optimal strategies:

to the firm $A-y_{1}=y_{2}=0 ; y_{3}=0,685, y_{4}=0,315$

to the firm $B-x_{1}=0,263, x_{2}=0,737$.

The cost of the game (i.e expected losses of the firm $A$ ) equals $-234.2 \$$.

\section{Statistical games and criteria for decision making}

Production processes are managed by implementing a sequence of solutions. In the absence of sufficiently complete information on the state of the management object, uncertainty arises in decision making ${ }^{2}$.

The reasons for this may be different: the inability to obtain information before the decision is made; very high information costs; inability to eliminate uncertainty due to objective nature. For example, the random nature of the demand for products makes it impossible to accurately predict the volume of its output.

In order to mitigate the adverse effects in each case, the degree of risk and the information available must be taken into account. In this case, the decision-maker enters a game relationship with some abstract person who can be conditionally called «nature».

In other words, the decision-maker must be able to find management decisions when nature does not consciously choose its optimal strategies. Any economic activity can be considered as a game with nature, about whose conditions there are some probability characteristics.

Nature's indifference to the game (win) and the opportunity for the decision-maker to obtain additional information about its condition

\footnotetext{
${ }^{2}$ Churchman W., Acof R., Arnoff L. Introduction to Operations Research. Moscow: Science, 1968, 488 p.
} 
distinguish the game from nature from a regular matrix game involving two conscious players.

Statistical games are the main model of decision theory in the context of partial uncertainty.

Let's return to the problem again - games with firms $A$ and $B$. Since such a game is usually not antagonistic, its solution cannot be considered optimal. In fact, the supplier company $B$ does not want to cause the firm Amaximum damage and therefore its reliability may be any, not necessarily the worst from the point of view of the company $A$ (the worst for the firm $A$ - supplier reliability 0.263 ).

If, for example, the reliability of firm $\mathrm{B} \boldsymbol{x}_{\mathbf{1}}=\mathbf{0}, \mathbf{4}$, and firm $A$ continue to apply the optimal mixed strategy for the antagonistic game, then the expected costs of firm $A$ do not decrease. Indeed,

$$
S(0,4)=0,685 \cdot S_{3}(0,4)+0,3 \cdot S_{4}(0,4)=
$$

$=0,685(60 \cdot 0,4-250)+0,315(-130 \cdot 0,4-200)=-234,2 y .0$.

where $\boldsymbol{S}_{\mathbf{3}}\left(\boldsymbol{x}_{\mathbf{1}}\right), \boldsymbol{S}_{\mathbf{4}}\left(\boldsymbol{x}_{\mathbf{1}}\right)$ are determined by relations (3), (4).

In order to reduce costs for such reliability of the supplier, it is necessary to abandon the optimal strategy and use, as shown above, the pure third strategy $A_{3}$ (see Fig. 1).

The costs are reduced to -226 USD.

Thus, the peculiarity of the solution of games with nature in the conditions of certainty is that a mixed strategy of nature is given, that is, all the probabilities of states are known:

$$
x_{j}, j=1,2, \ldots, n ; \sum_{j=1}^{n} x_{j}=1
$$

This allows for each $i$ pure strategy of the active player to calculate the mathematical expectation of his/her win against the known mixed strategy of nature by the formula

$$
S_{i}\left(x_{1}, \ldots, x_{n}\right)=\sum_{j=1}^{n} a_{i j} x_{j}, i=1,2, \ldots, m,
$$

where $a_{i j}$ - element of the payment matrix, located at the intersection of the $\mathrm{i}$-th row and the $\mathrm{j}$-th column: 


$$
A=\left(\begin{array}{cccccc}
a_{11} & a_{12} & \ldots & a_{1 j} & \ldots & a_{1 n} \\
a_{21} & a_{22} & \ldots & a_{2 j} & \ldots & a_{2 n} \\
\ldots & \ldots & \ldots & \ldots & \ldots & \ldots \\
a_{i 1} & a_{i 2} & \ldots & a_{i j} & \ldots & a_{i n} \\
\ldots & \ldots & \ldots & \ldots & \ldots & \ldots \\
a_{m 1} & a_{m 2} & \ldots & a_{m j} & \ldots & a_{m n}
\end{array}\right)
$$

The maximum element in the calculated column $\boldsymbol{S}_{\boldsymbol{i}}(\boldsymbol{i}=\overline{\mathbf{1}, \boldsymbol{m}})$ of mathematical expectations of winnings,

$$
S_{\text {max }}=\max _{i} S_{i}\left(x_{1}, \ldots, x_{n}\right),
$$

determines the most profitable strategy of the active player and quantifies the maximum possible winnings.

If there are two or more maximum elements in this column, then the respective strategies can be used, either purely or in any combination.

This approach to the solution of games against nature takes place only when the probabilities of the states of nature are given. Often decisions are made in the absence of information about such probabilities. Then, knowing the possible list of states of nature, consider them equally probable.

At the same time, the maximum mathematical expectation of winning (Laplace criterion) can be used to select the optimal strategy, but this criterion can only be used for an even distribution of probabilities $x_{i}=1 / n(i=1,2, \ldots, n)$.

Let us consider the other criteria that are applied to solve the games with nature under uncertainty conditions ${ }^{3}$.

\section{Wald's Maximin Criterion.}

In this case, such a solution is chosen that guarantees a win at least

$$
S_{B}=\max _{i} \min _{j} a_{i j} .
$$

With respect to the game under consideration, under any behavior of the supplier firm $B$ the firm $A$ may choose any of its pure strategies. There can be two consequences for each strategy. For guarantee, the company And takes into account the one that gives the smallest winnings. Write it down in the column of minimums of rows (tab. 3).

\footnotetext{
${ }^{3}$ Churchman W., Acof R., Arnoff L. Introduction to Operations Research. Moscow: Science, 2007, 2010 p.
} 
Table 3

\begin{tabular}{|c|c|c|c|}
\hline \multirow{2}{*}{$\begin{array}{c}\text { Cтратегiя } \\
\text { фірмн A }\end{array}$} & \multicolumn{2}{|c|}{ Crрaтегiя фірми $B$} & \multirow{2}{*}{$\begin{array}{c}\text { Мінімум } \\
\text { рядків }\end{array}$} \\
\hline & $B_{1}$ & $\boldsymbol{B}_{2}$ & \\
\hline$A_{1}$ & -100 & -400 & -400 \\
\hline $\mathrm{A}_{2}$ & -150 & -300 & -300 \\
\hline $\mathrm{A}_{3}$ & -190 & -250 & -250 (максимін) \\
\hline $\mathrm{A}_{4}$ & -330 & -200 & -330 \\
\hline Максимум стовпчиків & -100 & -200 (мінімакс) & \\
\hline
\end{tabular}

From these lines, you can choose the one with which this minimum win will be the maximum (-250). This is the optimal strategy of firm A, chosen in accordance with the Wald's criterion.

Table 3 also defines the minimax strategy of the firm $B$, for which the maximum payout is selected from each column and such strategy is accepted that gives the firm $A$ the minimal of these maximal payoffs.

In this case, the strategy of the firm $B$. is the second one. Thus, the maximin strategy $A_{3}$ of the firm $A$ neutralizes the minimax strategy $B_{2}$ of the firm $B$.

Obviously, the Wald's criterion can be seen as extreme pessimism in the assessment of circumstances. According to it, it is recommended to choose one of the alternative strategies, the pessimistic assessment of which is the best.

\section{Maximin criterionCriterion}

This criterion assumes that the state of nature will be most favorable for us, so we must choose a solution that provides the maximax gain among the maximum possible, i.e

$$
S_{m}=\max _{i} \max _{j} a_{i j}
$$

Using the maximax criterion in the problem under consideration, we obtain $S_{m}=-\$ 100$. This is in line with strategy $\boldsymbol{A}_{\mathbf{1}}$, that is, firm $A$ should not take any actions, assuming that the firm $B$ will apply the most favorable for itself strategy $B_{l}$.

In contrast to the Wald's criterion, the maximax criterion can be considered as extreme optimism in the assessment of the circumstances while making the decision. 


\section{Hurwitz's (pessimism - optimism) Criterion}

When choosing a solution instead of two extremes in the assessment of the situation (optimism - pessimism) it becomes logical to adhere to some intermediate position, which takes into account the possibility of both the worst and the best behavior of nature. Such a compromise criterion was suggested by Hurwitz.

In his opinion, we must determine the linear combination of the minimum and maximum payoffs for each decision and choose the strategy for which this value will be greatest:

$$
S_{r}=\max _{i}\left[\alpha \max _{j} a_{i j}+(1-\alpha) \min _{j} a_{i j}\right]
$$

where $\boldsymbol{\alpha}(\mathbf{0} \leq \boldsymbol{\alpha} \leq \mathbf{1})$ is the degree of optimism. When $\boldsymbol{\alpha}=\mathbf{0}$, the Hurwitz criterion goes to the maximum Waldo criterion; at $\boldsymbol{\alpha}=\mathbf{1}-$ matches the maximax criterion. The choice of the degree of optimism is influenced by the measure of responsibility: the greater the consequences of wrong decisions, the greater the desire to insure, the closer $\alpha$ to zero.

The influence of the degree of optimism on the choice of the solution in the problem under consideration is given in Table 4.

Table 4

\begin{tabular}{|c|c|c|c|c|c|c|c|c|c|}
\hline \multirow{2}{*}{ Cтратегія } & \multicolumn{8}{|c|}{ Ступінь оптимізму } \\
\cline { 2 - 10 } & $1 / 9$ & $2 / 9$ & $3 / 9$ & $4 / 9$ & $5 / 9$ & $6 / 9$ & $7 / 9$ & $8 / 9$ & 1 \\
\hline A1 & 370 & -340 & -310 & -280 & -250 & -220 & $-190^{*}$ & $-160^{*}$ & $-130^{*}$ \\
\hline A2 & -285 & -270 & -255 & -240 & -225 & $-210^{*}$ & -195 & -180 & -165 \\
\hline A3 & $-244^{*}$ & $-238^{*}$ & $-232^{*}$ & $-226^{*}$ & $-220^{*}$ & -214 & -208 & -202 & -196 \\
\hline A4 & -317 & -304 & -281 & -278 & -265 & -252 & -239 & -226 & -213 \\
\hline
\end{tabular}

Note. The value $\mathrm{S}_{\mathrm{r}}$ for each value $\mathrm{a}$ is marked with $a *$ *.

When $\alpha \leq 5 / 9$ Hurwitz's criterion recommends to the firm $A$ using strategy $A_{3}$, when $\mathbf{5} / \mathbf{9} \leq \boldsymbol{\alpha} \mathbf{2} / \mathbf{3}$ - strategy $A_{2}$, in other cases $-\boldsymbol{A}_{\mathbf{1}}$.

\section{Savage's minimax regret criterion}

The essence of this criterion is to choose such a decision so as not to allow excessively large losses, to which the wrong decision can lead. 
For this purpose, a «risk matrix» is built, the elements of which show how much damage we will bear if we do not choose the best solution for each state of nature.

The risk of a player when choosing a solution (strategy) $\boldsymbol{A}_{\boldsymbol{i}}$ under the conditions $\boldsymbol{B}_{\boldsymbol{j}}$ is the difference between the maximum win, available in these conditions, and the win that the player will receive in the same conditions using the strategy $\boldsymbol{A}_{\boldsymbol{i}}$, Let us denote this value by $r_{i j}$.

If the player knew in advance the future state of nature $\Pi_{j}$, he would choose a strategy that would correspond to the maximum element in the specified column: max $a_{i j}$. Then, by definition, the risk is equal to

$$
\boldsymbol{r}_{i j}=\max _{i} a_{i j}-a_{i j}
$$

The risk matrix is constructed as follows:

1) the largest element is determined for each state of nature (column);

2) the risk matrix element is obtained by subtracting the corresponding element of the payment matrix from the maximum element of this column.

Savage's criterion recommends that in uncertainty conditions, one should choose a solution that provides minimal rate of the maximum risk:

$$
S_{c}=\min _{i} \max _{j} r_{i j}=\min _{i} \max _{j}\left(\max _{i} a_{i j}-a_{i j}\right) .
$$

The risk matrix for the problem under consideration is given in Table. 5.

Table 5

\begin{tabular}{|c|c|c|c|}
\hline Стратегія & $\mathbf{B}_{\mathbf{1}}$ & $\mathbf{B}_{\mathbf{2}}$ & Максимум рнзнків \\
\hline $\mathrm{A}_{1}$ & 0 & 200 & 200 \\
\hline $\mathrm{A}_{2}$ & 50 & 100 & 100 \\
\hline $\mathrm{A}_{3}$ & 90 & 50 & $90^{*}$ \\
\hline $\mathrm{A}_{4}$ & 130 & 0 & 130 \\
\hline
\end{tabular}

To the right of the risk matrix there is the maximum risk column for each strategy $\boldsymbol{A}_{\boldsymbol{i}}$. Minimax risk is reached when choosing $\boldsymbol{A}_{\mathbf{3}}: \boldsymbol{S}_{\boldsymbol{c}}=\mathbf{9 0}$. 


\section{Bayes-Laplace criterion}

Applying this criterion, they depart from the conditions of complete uncertainty (lack of information about the state of nature), believing that a certain probability of their occurrence can be used for the probable states of nature.

In this case, determining the mathematical expectation of winning for each decision, they choose the one that provides the highest value of the win:

$$
S_{\text {БЛ }}=\max _{i} \sum_{j=1}^{n} a_{i j} X_{j} .
$$

The Bayes-Laplace principle can be applied if the states of nature under study and the decisions made are many times repeated.

Then, for example, statistical methods, based on the frequency of occurrence of certain states of nature in the past, can estimate the likelihood of their occurrence in the future.

For single solutions that do not repeat, the Bayes-Laplace principle cannot be applied even when the states of nature are repeated.

This is because such solutions violate the stationarity of the probability distribution of nature.

Let us suppose that firm $A$, before making a decision, has analyzed how accurately the supplier firm $B$ had previously followed the delivery deadlines, and has determined that in 25 cases out of 100 raw materials were delayed. It follows that the state $\boldsymbol{B}_{\mathbf{1}}$, can be assigned with the probability $X_{1}=0,75$, and the state $B_{2}$ - with the probability $X_{2}=0,25$. Then, according to the Bayes-Laplace criterion, the solution (strategy) $A_{l}$ is optimal (Table 6).

\begin{tabular}{|c|c|}
\hline Стратегія & $\sum_{j=1}^{n} a_{i j} X_{j}$ \\
\hline $\mathrm{A}_{1}$ & $-175,0^{*}$ \\
\hline $\mathrm{A}_{2}$ & $-187,5$ \\
\hline $\mathrm{A}_{3}$ & $-205,0$ \\
\hline $\mathrm{A}_{4}$ & $-297,5$ \\
\hline
\end{tabular}

Table 6 
The criteria listed do not draw out the full variety of decision selection criteria under uncertainty, including the criteria for selecting the best mixed strategies.

The solutions recommended by the considered criteria for the studied task are given in Table. 7.

Table 7

\begin{tabular}{|c|c|c|c|c|c|c|c|}
\hline \multirow[b]{2}{*}{ Crpareriï } & \multicolumn{6}{|c|}{ Kpurepiti } & \multirow{2}{*}{ 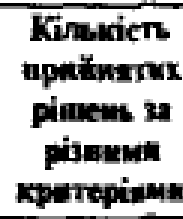 } \\
\hline & Barang & $\begin{array}{l}\text { Manen: } \\
\text { mexcenuhi }\end{array}$ & Typmanan & Ceniuma & Raurrace & $\begin{array}{l}\text { Exalexn - } \\
\text { Jharaca }\end{array}$ & \\
\hline$A_{t}$ & & + & + & & & + & 3 \\
\hline $\mathbf{A}_{2}$ & & & + & & & + & 2 \\
\hline $\boldsymbol{A}_{4}$ & + & & + & + & + & + & 5 \\
\hline$A_{4}$ & & & & & & & 0 \\
\hline
\end{tabular}

The table shows that the optimal behavior depends largely on the accepted optimization criterion. Therefore, the selection of the criterion is the most important question in the study of operations.

Each choice of criterion leads to the approval of a decision, which may differ from the decision made in accordance with another criterion. However, the situation is never so uncertain that it is impossible to obtain at least partial information on the probability of the distribution of the states of nature in the situation being analyzed.

In this case, estimating the probability distribution of the states of nature, they apply the Bayes-Laplace criterion or conduct an experiment to clarify the behavior of nature.

\section{Modeling Effectiveness of Information Retention Costs under Uncertainty Conditions}

In games with nature, making one or the other decision, we can not find in advance in what state it is at the time of implementation of the decision, even when we know the probability distribution of its states. Therefore, the solution, that is the best for such a probability distribution of the states of nature, will not be better than the state which nature will truly take ${ }^{4}$.

\footnotetext{
${ }^{4}$ Akof R., Sasiena M. Fundamentals of Operations Research. Moscow: World, 2007, 2010 p.
} 
It follows from the Bayes-Laplace criterion that the solution is the player's strategy $A_{i}$, which provides the maximum average win. This strategy is best in a situation where nature «chooses» its states by chance, but with a known law of distribution.

However, the maximum average win is not the maximum attainable win. Indeed, let us imagine a perfect case when we know the future state of nature precisely before deciding. Then we can apply that pure strategy that allows against this state of nature $\Pi_{j}$ to get a maximum gain of $\boldsymbol{v}_{j}=$ $\max _{i} a_{i j}$

With a sufficiently large number of repetitions of the game in terms of full prediction, the average maximum win will be equal to

$$
S=\sum_{J=1}^{n} v_{j} X_{j}
$$

Since $\boldsymbol{a}_{\boldsymbol{i} j} \leq \boldsymbol{v}_{\boldsymbol{j}}$, the value (5) always does not exceed the value (6). Then, the difference

$$
d=\sum_{j=1}^{n} v_{j} X_{j}-\max _{i} \sum_{j=1}^{n} a_{i j} X_{j}
$$

is the magnitude of the additional average gain due to an accurate knowledge of the future state of nature at the time of making the decision.

Suppose that there is reliable information (an ideal experiment) that accurately predicts the future state of nature. We estimate the expediency of acquiring such information (conducting such an experiment) at the cost of obtaining it $p$. Since the additional gain (excluding the cost of information) is $(1-c$, purchase is expedient when $\breve{u}-c>0$, i.e taking into account (7) when

$$
\sum_{j=1}^{n} v_{j} X_{j}-\max _{i} \sum_{j=1}^{n} a_{i j} X_{j}>c .
$$

And if not, the acquiring of Information (experiment) has to be abandoned and the strategy $A_{i}$, which provides the maximum average win.

Let us now return to the aforecited problem, when the reliability of the supplier company $B$ is, for example, 0,6 , and the cost of reliable information (ideal experiment) is $\$ 40$ per day.

The table 8 shows the costs (benefits) of the company $A$. 
Table 8

\begin{tabular}{|c|c|c|c|}
\hline \multirow[b]{2}{*}{$\begin{array}{l}\text { Pimeнnя } \\
\text { фірмк A }\end{array}$} & \multicolumn{2}{|c|}{ Стратегія фірми В } & \multirow[b]{2}{*}{$\begin{array}{c}\text { Середніӓ вяграm фірмк } A \\
\text { nрв } X_{1}=0,6\end{array}$} \\
\hline & $\mathrm{B}_{1}$ & $\mathbf{B}_{2}$ & \\
\hline$\widehat{A_{1}}$ & -100 & -400 & -220 \\
\hline$\overline{A_{2}}$ & -150 & -300 & -210 \\
\hline $\mathrm{A}_{3}$ & -190 & -250 & -214 \\
\hline$A_{4}$ & -330 & -200 & -278 \\
\hline $\begin{array}{l}\text { Макскммальнкй } \\
\text { виграш фірмн А }\end{array}$ & -100 & -200 & -140 \\
\hline
\end{tabular}

Obviously, if the delivery is timely (state $\boldsymbol{B}_{\mathbf{1}}$ ), the best solution is $A_{I}$ and the costs are equal to $\$ 100$, if there is no supply (state $B_{2}$ ), is the best solution D, and the costs are $\$ 200$.

The average maximum payout (minimum cost) of the firm $A$ will be $S=-100 \cdot 0,6-200 \cdot 0,4=-140 y .0 .$, which is greater than the maximum average payout, which equals to $\$ 210$, for $-\mathbf{1 4 0}-\mathbf{2 1 0}=\mathbf{7 0}$ y. o.

As the information on timely delivery costs the company $A$ the amount of $c=\$ 40$, it receives an additional gain of $c=\$ 70-\$ 40=\$ 30$ a day. Obviously, the acquisition of such information is appropriate.

The condition for the expediency of acquiring information (experiment) (8) can be written as

$$
\min _{i} \sum_{j=1}^{n}\left(v_{j}-a_{i j}\right) X_{j}>c,
$$

where $\boldsymbol{v}_{\boldsymbol{j}}-\boldsymbol{a}_{\boldsymbol{i} \boldsymbol{j}}=\boldsymbol{r}_{\boldsymbol{i} \boldsymbol{j}}$ is nothing but risk (see $\S 3.4$ ) and the sum on the left (9) is the average risk. Therefore, an acquisition (experiment) is appropriate when the cost of obtaining it is less than the minimum average risk:

$$
\min _{i} \sum_{j=1}^{n} X_{j} r_{i j}>c .
$$

Above, the situation where we can accurately determine the future state of nature has been considered. However, more often, additional information can only clarify the a priori probability distribution of these states. In this case, they are talking about clarifying information (a nonideal experiment). Now instead of a clear answer «Tomorrow the delivery 
will happen» or «Tomorrow the delivery will not happen» we will most likely receive answers that can be formulated as follows:

\section{$C_{1}$-the supplier is more reliable than we think;}

$C_{2}$ - the supplier reliability is almost the same as we think;

$C_{3}-$ the supplier is less reliable than we think.

Each of these results comes with some probability, the distribution of such probabilities depends on the states of nature, that is, on the conditions in which information is obtained (an experiment is conducted). Let us suppose that the multiple experiments that were conducted before, allowed us to collect data on the conditional probabilities of the results of experiments $\boldsymbol{P}\left(\boldsymbol{C}_{\boldsymbol{i}} / \boldsymbol{B}_{\boldsymbol{j}}\right)$, which are given in Table 9.

Table 9

\begin{tabular}{|c|c|c|c|}
\hline \multirow{2}{*}{$\begin{array}{c}\text { Результат } \\
\text { експернменту }\end{array}$} & \multicolumn{2}{|c|}{ Стан постачальнкка } & $\begin{array}{c}\text { Повна имовірність } \\
\text { результату при } \boldsymbol{X}_{\mathbf{1}}=\mathbf{0 , 6}\end{array}$ \\
\cline { 2 - 4 } & $\mathbf{B}_{1}$ & $\mathbf{B}_{2}$ & 0,38 \\
\hline $\mathrm{C}_{1}$ & 0,5 & 0,2 & 0,36 \\
\hline $\mathrm{C}_{2}$ & 0,4 & 0,3 & 0,26 \\
\hline $\mathrm{C}_{3}$ & 0,1 & 0,5 & \\
\hline
\end{tabular}

Knowing the conditional probabilities of the results $\boldsymbol{P}\left(\boldsymbol{C}_{\boldsymbol{i}} / \boldsymbol{B}_{\boldsymbol{j}}\right)$ and the probabilities of the states of nature $\boldsymbol{X}_{\boldsymbol{j}}$, one can calculate the full probabilities of the results $\boldsymbol{P}\left(\boldsymbol{C}_{\boldsymbol{i}}\right)$ by the formulas

$$
P\left(C_{i}\right)=\sum_{j=1}^{n} P\left(C_{i} / B_{j}\right) X_{j}
$$

For probability $\boldsymbol{X}_{\mathbf{1}}=\mathbf{0}, \mathbf{6}$, they are:

$$
\begin{aligned}
& P\left(C_{1}\right)=\sum_{j=1}^{2} P\left(C_{1} / B_{j}\right) X_{j}=0,5 \cdot 0,6+0,2 \cdot 0,4=0,38 \\
& P\left(C_{2}\right)=\sum_{j=1}^{2} P\left(C_{2} / B_{j}\right) X_{j}=0,4 \cdot 0,6+0,3 \cdot 0,4=0,36
\end{aligned}
$$




$$
P\left(C_{3}\right)=\sum_{j=1}^{2} P\left(C_{3} / B_{j}\right) X_{j}=0,1 \cdot 0,6+0,5 \cdot 0,4=0,26
$$

and are given in the last column of the table 9. Knowing them, you can determine the specified probabilities of the state of nature after the experiment.

Bayes formulas serve to calculate the posterior (post-experimental) the distribution of probabilities of the state of nature.

$$
X_{j}\left(C_{i}\right)=\frac{X_{j} P\left(C_{i} / B_{j}\right)}{P\left(C_{i}\right)}
$$

We calculate this distribution if the result of the experiment was $\boldsymbol{C}_{\mathbf{1}}$ :

$$
\begin{aligned}
& X_{1}\left(C_{1}\right)=\frac{X_{1} P\left(C_{1} / B_{1}\right)}{P\left(C_{1}\right)}=\frac{0,6 \cdot 0,5}{0,38}=0,79 ; \\
& X_{2}\left(C_{1}\right)=\frac{X_{2} P\left(C_{1} / B_{2}\right)}{P\left(C_{1}\right)}=\frac{0,4 \cdot 0,2}{0,38}=0,21 ;
\end{aligned}
$$

Now (after receiving the information, conducting the experiment) the reliability of the supplier instead of 0.6 is estimated at 0.79 . The best

\begin{tabular}{|c|c|c|c|c|c|c|}
\hline \multirow{2}{*}{$\begin{array}{l}\text { Рішення } \\
\text { фірми А }\end{array}$} & \multicolumn{2}{|c|}{ Стан фірми В } & \multicolumn{4}{|c|}{$\begin{array}{l}\text { Середні внтрятн фірми } \boldsymbol{A} \\
\text { прн надійності фірмн В } X_{1}\end{array}$} \\
\hline & $\mathbf{B}_{1}$ & $\overline{\mathbf{B}_{2}}$ & 0,6 & 0,79 & 0,667 & 0,231 \\
\hline$\widehat{A_{1}}$ & -100 & -400 & -220 & -163 & -200 & $-331,1$ \\
\hline$\overline{A_{2}}$ & -150 & -300 & -210 & $-181,5$ & -200 & $-265,7$ \\
\hline $\overrightarrow{A_{3}}$ & -190 & -250 & -214 & $-202,5$ & -210 & -236 \\
\hline $\mathrm{A}_{4}$ & -330 & -200 & -278 & -303 & $-286,7$ & $-230,1$ \\
\hline
\end{tabular}
strategy of the company $A$ according to Bayes-Laplace criterion instead of $A_{2}$ will become $A_{l}$ (table 10 ), which provides the minimum of costs $-\$ 163$.

Table 10

Table 10 shows that without additional information (conducting the experiment), the costs were in the amount of $-\$ 210$, after that they became $-\$ 163$. The extra payoff is $-163-(-210)=\$ 47$. The cost of obtaining information (conducting the experiment) is $\$ 40$. But these 
calculations are still not enough to conclude that it is advisable to acquire information, since the result could have been different $\left(\mathrm{C}_{2}\right.$ or $\mathrm{C}_{3}$, see Table 9), and additional payoffs having these results are still unknown. Let us calculate them.

If the result of the experiment is $\mathrm{C}_{2}$, the posterior probabilities of the states of the firm $B$ are

$$
\begin{aligned}
& X_{1}\left(C_{2}\right)=\frac{X_{1} P\left(C_{2} / B_{1}\right)}{P\left(C_{2}\right)}=\frac{0,6 \cdot 0,4}{0,36}=0,667 ; \\
& X_{2}\left(C_{2}\right)=\frac{X_{2} P\left(C_{2} / B_{2}\right)}{P\left(C_{2}\right)}=\frac{0,4 \cdot 0,3}{0,36}=0,333 ;
\end{aligned}
$$

For reliability of the supplier company $B$ average costs of the company $A$ are shown in table 10 . It is seen that the solutions $A$, or $A_{2}$ will be optimal or any combination of these strategies, the win is $\$ 200$

If the result of the experiment is $\mathrm{C}_{3}$, then

$$
\begin{aligned}
& X_{1}\left(C_{3}\right)=\frac{X_{1} P\left(C_{3} / B_{1}\right)}{P\left(C_{3}\right)}=\frac{0,6 \cdot 0,1}{0,26}=0,231 ; \\
& X_{2}\left(C_{3}\right)=\frac{X_{2} P\left(C_{3} / B_{2}\right)}{P\left(C_{3}\right)}=\frac{0,4 \cdot 0,5}{0,26}=0,769 ;
\end{aligned}
$$

With the reliability of the company $B 0,231$ the minimum average cost of the company $A$, which is equal to $\$ 230,1$, is achieved when applying the strategy $\boldsymbol{A}_{\mathbf{4}}$.

Using the full probabilities of information obtaining results, we calculate the average cost (gain) of the firm $A$ :

$-1630.38-2000.36-230.010 .26=-193.8 \$$

In the absence of additional information, they are -210u.o. The extra payoff is $-163-(-210)=\$ 47$. Therefore, at the cost of additional information $\$ 40$ its acquisition is inappropriate.

\section{Determining the optimal inventory of commercial companies}

Let us by $x$ denote the market demand for the products of a trading firm for some fixed period of time (day, week, month, etc.), which is unknown in advance. Units of products for sale can be both physical (kilograms, liters, etc.) or monetary. Let us suppose that unrealized in this 
period products lose their consumer qualities during storage and can not be sold in the next period ${ }^{5}$.

Let us hereafter using $C_{l}$ denote the sum of the prime cost and additional costs of storage of a unit of production which was not realized in the mentioned period of time due to the fact that the demand for it was less than projected, and using $\mathrm{C}_{2}$ we denote the loss of profit per unit of production, which is caused by its absence, when the demand for it exceeds its quantity $\mathrm{d}$, which is available in the firm.

In view of the above designations, the loss of the firm is determined by the function

$$
V(x, s)=\left\{\begin{array}{l}
C_{1}(s-x), \text { коли } s \geq x . \\
C_{2}(x-s), \text { коли } s<x .
\end{array}\right.
$$

We will consider the demand for products $x$ as a random variable with a distribution function $F(x)$, which can be determined on the basis of statistical observations or other information. Then the losses of firm $V(x, s)$, determined by the ratio (10), are a function of the random value $x$ (demand) and the value of the product stock $s$, and the task of defining the optimal stock of products of a trading company can be considered as a statistical game with «nature». Player $A$ is a trading company, player $B$ is a certain conditional customer (market) with a known distribution function $F(x)$.

The purpose of the company is to find such a value of the inventory $s$, that would minimize the mathematical expectation (average)

$$
[\mathbf{V}(\mathbf{x}, \mathbf{s})]=\int_{-\infty}^{\infty} \mathbf{V}(\mathbf{x}, \mathbf{s}) \mathbf{d F}(\mathbf{x})
$$

of its costs.

Substituting in (11) the function of losses (10), we obtain

$$
\begin{gathered}
M[V(x, s)]=C_{1} \int_{-\infty}^{s}(s-x) d F(x)+C_{2} \int_{s}^{\infty}(x-s) d F(x)= \\
=C_{1}\left[s \int_{-\infty}^{s} d F(x)-\int_{-\infty}^{s} x d F(x)\right]+C_{2}\left[\int_{s}^{\infty} x d F(x)-s \int_{s}^{\infty} d F(x)\right]= \\
=C_{1}\left[s F(s)-\int_{-\infty}^{s} x d F(x)\right]
\end{gathered}
$$

\footnotetext{
${ }^{5}$ Degtyarev Yu.I. Operations Research. Moscow: Higher chool, 1986, 320 p.
} 


$$
\begin{gathered}
+C_{2}\left[\int_{s}^{\infty} x d F(x)+\int_{-\infty}^{s} x d F(x)-\int_{-\infty}^{s} x d F(x)-s(1-F(s))\right]= \\
=C_{1}\left[s F(s)-\int_{-\infty}^{s} x d F(x)\right]+C_{2}\left[M[x]-\int_{-\infty}^{s} x d F(x)-s(1-F(s))\right]= \\
=\left(C_{1}+C_{2}\right) s F(s)-C_{2} s-\left(C_{1}+C_{2}\right) \int_{-\infty}^{s} x d F(x)+C_{2} M[x],
\end{gathered}
$$

where $\mathrm{M}[\mathrm{x}]$ denotes the mathematical expectation of the random variable $\mathrm{x}$.

To find the minimum value of the mathematical expectation $\boldsymbol{M}[\boldsymbol{V}(\boldsymbol{x}, \boldsymbol{s})]$, which is a function of the inventory $\mathrm{t}$, we equate the first derivative of this function to zero on the variable $s$ :

$$
\begin{gathered}
\frac{d M[V(x, s)]}{d s}=\left(C_{1}+C_{2}\right)[F(s)+s f(s)]-C_{2}-\left(C_{1}+C_{2}\right) s f(s)= \\
=\left(C_{1}+C_{2}\right) F(s)-C_{2}=0,
\end{gathered}
$$

where $\boldsymbol{f}(\boldsymbol{s})\left(\boldsymbol{f}(\boldsymbol{s})=\frac{\boldsymbol{d} \boldsymbol{F}}{\boldsymbol{d} \boldsymbol{s}}\right)$ denotes the probability density of demand distribution at point $\mathrm{s}$.

From relation (12), which is the equations, it implies that the optimal value of the inventory of trading company $5_{0}$, which minimizes its losses, satisfies the condition

$$
F\left(s_{0}\right)=\frac{C_{2}}{C_{1}+C_{2}}
$$

By definition $\boldsymbol{F}\left(\boldsymbol{s}_{\mathbf{0}}\right)=\boldsymbol{P} \mid\left(\boldsymbol{x}<\boldsymbol{s}_{\mathbf{0}}\right)$, i.e equality (13) means that the optimal value of the inventory $\mathrm{s}_{0}$ should meet a requirement that the probability that demand is less than $\mathrm{s}_{0}$ is equal to $\frac{C_{2}}{C_{1}+C_{2}}$.

A simple algorithm for determining $\mathrm{s}_{0}$ follows from the latter. On the basis of statistical observations a graph of the distribution function (cumulative) is constructed. Graphically or from the analytic expression of the distribution function $\mathrm{F}(\mathrm{x})$ we find the following value $\mathrm{s}_{0}$, for which equation (13) works. If the distribution is close to known, for example, 
normal, the value $\boldsymbol{s}_{\mathbf{0}}$ can be determined from the tables of normal distribution.

Let us consider how this is done in practice.

Suppose that the optimal value of inventory should be determined when $\mathrm{C}_{1}=0,6, \mathrm{C}_{2}=0,4$ and we have the statistical observations of daily demand for products over 31 days, which are shown as income (Table 11).

Table 11

\begin{tabular}{|l|c|c|c|c|c|c|c|c|c|c|}
\hline $\begin{array}{l}\text { Дохід, } \\
\text { у. о. }\end{array}$ & $0-2$ & $2-4$ & $4-6$ & $6-8$ & $8-10$ & $10-12$ & $12-14$ & $14-16$ & $16-18$ & $18-20$ \\
\hline Частота & 0 & 1 & 2 & 4 & 6 & 7 & 5 & 3 & 2 & 1 \\
\hline $\begin{array}{l}\text { Відносні } \\
\text { частоти }\end{array}$ & 0 & 0,03 & 0,06 & 0,13 & 0,20 & 0,23 & 0,16 & 0,10 & 0,06 & 0,03 \\
\hline $\begin{array}{l}\text { Накопи- } \\
\text { чені } \\
\text { частоти }\end{array}$ & 0 & 0,03 & 0,09 & 0,22 & 0,42 & 0,65 & 0,81 & 0,91 & 0,97 & 1,00 \\
\hline
\end{tabular}

Based on these data, we calculate frequencies, relative frequencies, cumulative frequencies (cumulative line) and build a distribution graph (Fig. 3) using known formulas from statistics.

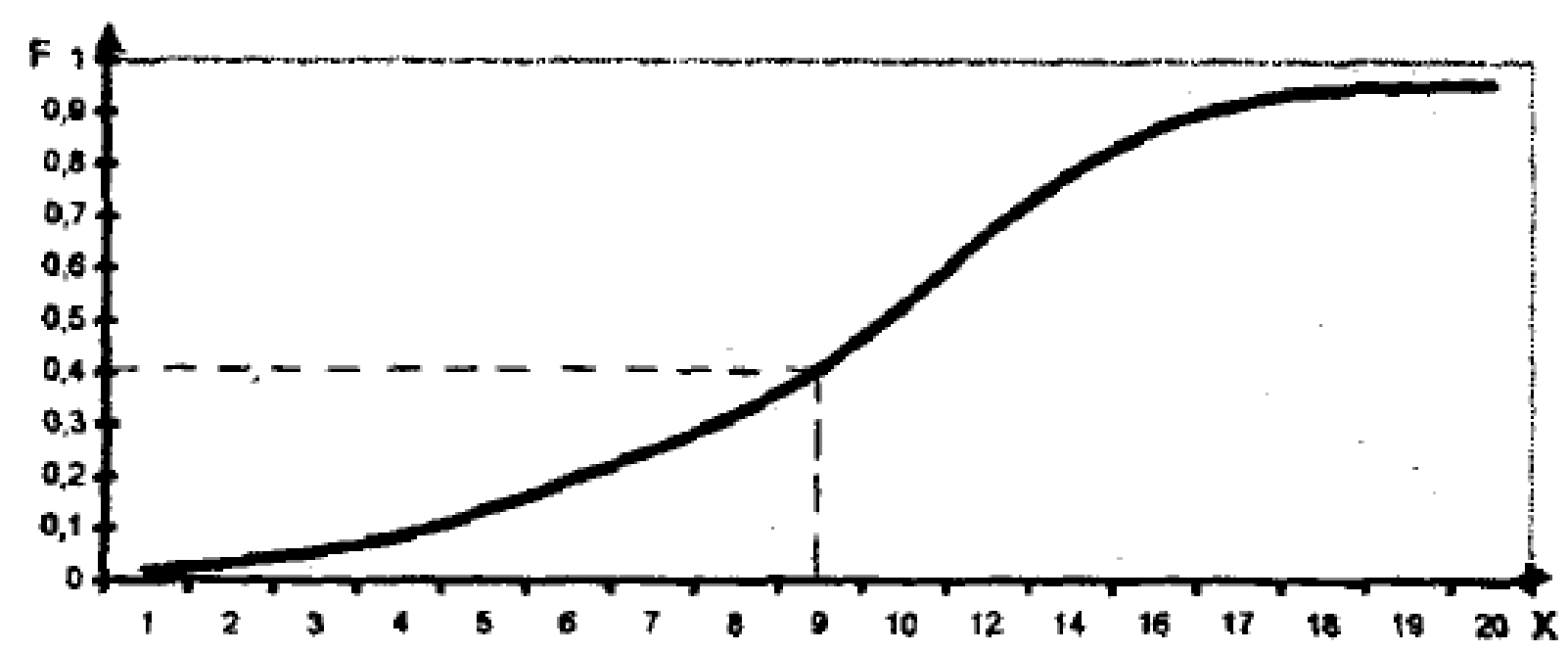

Fig. 3

Next, by the formula (13) we calculate

$$
F\left(s_{0}\right)=\frac{C_{2}}{C_{2}+C_{1}}=\frac{0,4}{0,6+0,4}=0,4
$$


and graphically determine $\$ \boldsymbol{s}_{\mathbf{0}} \approx \mathbf{9}$, where the needed optimal value of the daily stock of products of a trading firm will be given in a value that minimizes the mathematical expectation (average value) of its losses per one day.

Similar to the above mentioned, calculations can be made to predict the optimal stock of production of firms for any period of time.

\section{REFERENCES}

1. Kofman A. Methods and models of operations research. Moscow: World, 1977, 432p.

2. Churchman W., Acof R., Arnoff L. Introduction to Operations Research. Moscow: Science, 1968, 488 p.

3. Churchman W., Acof R., Arnoff L. Introduction to Operations Research. Moscow: Science, 2007, 2010 p.

4. Akof R., Sasiena M. Fundamentals of Operations Research. Moscow: World, 2007, 2010 p.

5. Degtyarev Yu. I. Operations Research. Moscow: Higher chool, 1986, 320 p.

Information about the author: Muliava O. M.

Candidate of Physical and Mathematical Sciences, Associate Professor, Deputy Dean of the National University of Food Technology 